Received: 17 July 2017

Accepted: 2 October 2017

Published online: 18 October 2017

\section{Direct Production of Furfural in One-pot Fashion from Raw Biomass Using Brønsted Acidic lonic Liquids}

\author{
Babasaheb M. Matsagar ${ }^{1,2,3}$, Shahriar A. Hossain ${ }^{4,5}$, Tofazzal Islam ${ }^{6}{ }^{6}$, Hatem R. Alamri ${ }^{7}$, \\ Zeid A. Alothman ${ }^{8}$, Yusuke Yamauchi ${ }^{4,5,9}$, Paresh L. Dhepe ${ }^{1,2} \&$ Kevin C.-W. Wu ${ }^{3}$
}

The conversion of raw biomass into $C 5$-sugars and furfural was demonstrated with the one-pot method using Brønsted acidic ionic liquids (BAILs) without any mineral acids or metal halides. Various BAILs were synthesized and characterized using NMR, FT-IR, TGA, and CHNS microanalysis and were used as the catalyst for raw biomass conversion. The remarkably high yield (i.e. $88 \%$ ) of $\mathrm{C} 5$ sugars from bagasse can be obtained using 1-methyl-3(3-sulfopropyl)-imidazolium hydrogen sulfate ([ $\left.\left.\mathrm{C}_{3} \mathrm{SO}_{3} \mathrm{HMIM}\right]\left[\mathrm{HSO}_{4}\right]\right)$ BAIL catalyst in a water medium. Similarly, the $\left[\mathrm{C}_{3} \mathrm{SO}_{3} \mathrm{HMIM}\right]\left[\mathrm{HSO}{ }_{4}\right]$ BAIL also converts the bagasse into furfural with very high yield (73\%) in one-pot method using a water/toluene biphasic solvent system.

Lignocellulosic biomass, which comprises cellulose, hemicellulose, and lignin, is an excellent alternative to fossil feedstock for the synthesis of biochemical and biofuels. For example, furfural is one of the top 30 biomass-derived platform chemicals according to U.S. Department of Energy ${ }^{1}$. Typically furfural is mostly produced from xylose or xylan (hemicellulose) using the acid catalyst ${ }^{2-4}$. The acid hydrolysis of xylan into xylose and successive dehydration of xylose will produce furfural. Xylan is found in large quantity in lignocellulosic biomass such as bagasse, wheat straw, corn cob, rice husk, cotton stalk and jute. Therefore, if furfural production is carried out in a one-pot method using xylan-rich raw biomass, then it is possible to develop a cost-effective method for the synthesis of furfural.

Some reports have shown the conversion of raw biomass into $\mathrm{C} 5$ sugars $(73 \%$ yield using $\mathrm{HCl}$ ) and furfural by using mineral acid and solid acid as catalysts (e.g. 55\% yield using $\mathrm{H}_{2} \mathrm{SO}_{4} ; 62 \%$ and $42 \%$ yields using $\mathrm{H} \beta$ and HMOR zeolites, respectively $)^{5-7}$. However, the problem with these reported methods is their complicated reaction process (i.e. the reactions were carried out in more than one step). As it is understood that for the conversion of raw biomass into C5 sugars, and furfural, it is critical to pretreat the raw biomass for separating hemicellulose from lignocellulosic biomass and then breaking its rigid framework ${ }^{8-10}$. After that, the pretreated hemicellulose is then converted into C5 sugars and further into furfural ${ }^{11}$. Previously one-pot conversion of bagasse was reported using an acidic solid catalyst (i.e. HUSY with $\mathrm{Si} / \mathrm{Al}=15$ ), but the yields of products were low (i.e. $20 \%$ (xylose + arabinose) and 55\% furfural) ${ }^{12}$. In addition, it was also reported that the solid acidic catalyst was not stable under reaction conditions ${ }^{12}$. These previous studies indicated that the mineral acids and solid acids used for the conversion of raw biomass have several drawbacks: (1) they are not recyclable and (2) they make the reaction system more corrosive, which increases the capital cost ${ }^{7,13}$.

Combining ionic liquids (ILs) with mineral or solid acids is a resolution for efficient xylose-to-furfural conversion. For example, it was reported that the verity of catalysts (i.e. $\mathrm{CrCl}_{3}, \mathrm{AlCl}_{3}, \mathrm{HCl} \mathrm{CuCl}, \mathrm{H}_{3} \mathrm{PO}_{4}, A$ mberlyst-15, $\mathrm{LiCl}$, etc. $)^{8,14,15}$ in a 1-butyl-3-methylimidazolium chloride ([BMIM] [Cl]) IL system for converting xylose and xylan to furfural with a high yield (10-84\% furfural yield from xylan). The use of acidic ILs was also reported for

${ }^{1}$ Catalysis \& Inorganic Chemistry Division, CSIR-National Chemical Laboratory, Dr. Homi Bhabha Road, Pune, 411008 , India. ${ }^{2}$ Academy of Scientific and Innovative Research (AcSIR), New Delhi, 110 025, India. ${ }^{3}$ Department of Chemical Engineering, National Taiwan University, No. 1, Sec. 4, Roosevelt Road, Taipei, 10617, Taiwan. ${ }^{4}$ International Center for Materials Nanoarchitectonics (MANA), National Institute for Materials Science (NIMS), 1-1 Namiki, Tsukuba, Ibaraki, 305-0044, Japan. ${ }^{5}$ Australian Institute for Innovative Materials (AIIM), University of Wollongong, Squires Way, North Wollongong, NSW, 2500, Australia. ${ }^{6}$ Department of Biotechnology, Bangabandhu Sheikh Mujibur Rahman Agricultural University, Gazipur, 1706, Bangladesh. ${ }^{7}$ Physics Department, Jamoum University College, Umm Al-Qura University, Makkah, 21955, Saudi Arabia. ${ }^{8}$ Advanced Materials Research Chair, Chemistry Department, College of Science, King Saud University, Riyadh, 11451, Saudi Arabia. ${ }^{9}$ School of Chemical Engineering \& Australian Institute for Bioengineering and Nanotechnology (AIBN), The University of Queensland, Brisbane, QLD 4072, Australia. Correspondence and requests for materials should be addressed to P.L.D. (email: pl.dhepe@ncl.res.in) or K.C.-W.W. (email: kevinwu@ntu.edu.tw) 
$\mathrm{H}_{2} \mathrm{O}+$ Toluene/BAIL

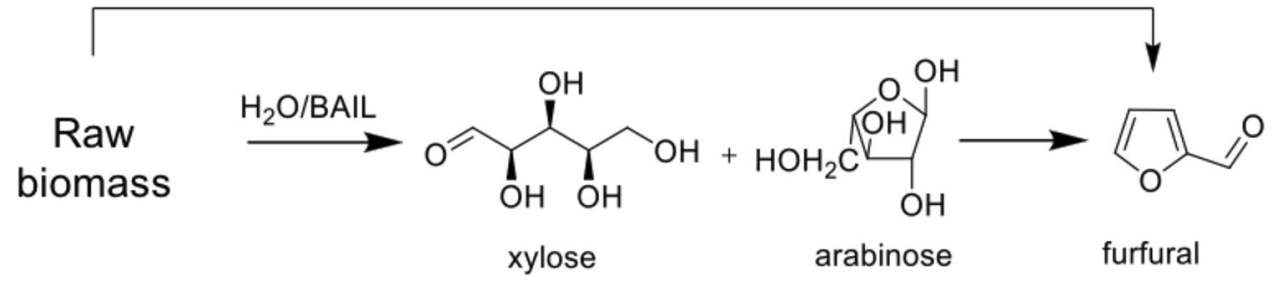

Figure 1. Conversion of raw biomass into C5 sugars and furfural in the one-pot method.

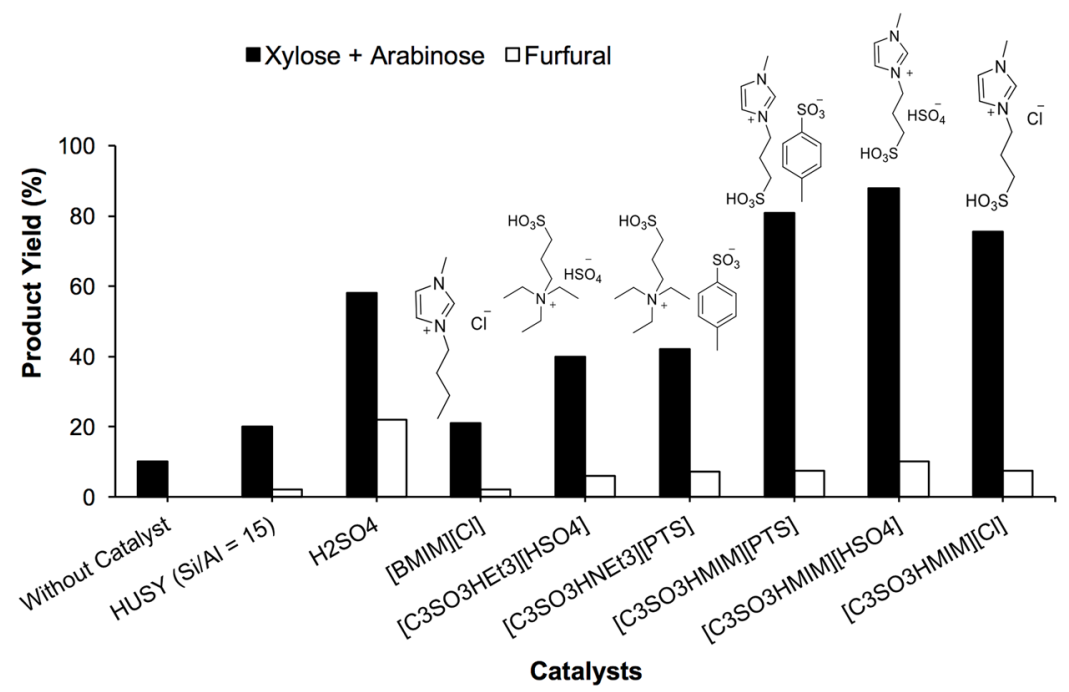

Figure 2. Catalyst evaluation study for processing of BG (I) into C5 sugars; Reaction condition: BG (I) (2 g), catalyst $(0.24 \mathrm{~g}), \mathrm{H}_{2} \mathrm{O}(60 \mathrm{~mL}), 160^{\circ} \mathrm{C}, 1 \mathrm{~h}$.

the chitosan conversion to $\mathrm{HMF}^{16}$. However, in these reactions, a large quantity of ILs was used ( $2 \mathrm{~g}$ IL for $38 \mathrm{mg}$ of xylan) and thus the separation of products becomes very difficult, in addition to a huge cost of expensive ILs.

To overcome the drawbacks associated with the solid acid and mineral acid catalysts, many pioneering studies have utilized acidic ILs for the production of 5-hydroxymethylfurfural (HMF) and furfural from C6 and C5 sugar, respectively ${ }^{17-20}$. It is known that the world's annual production of crops is very high ${ }^{21}$ (ESI; Table S1). After utilizing the edible part of all these crops, huge quantity of non-edible raw biomass is produced. Hence our aim is to use non-edible biomass for the production of C5 sugars followed by the C5 sugars-to-furfural conversion, as shown in Fig. 1. Here we present the use of a series of recyclable BAILs as the catalyst for the production of C5 sugars and furfural directly from raw biomass in a one-pot fashion. We believe our strategy would significantly enhance the efficacy of raw biomass conversion by using recyclable BAIL catalysts.

\section{Results and Discussion}

Catalyst evaluation: processing raw biomass into $\mathbf{C}$ sugars. The catalytic performance of various BAIL-based catalysts for the conversion of the raw biomass (Bagasse (I)) to C5 sugars is summarized in Fig. 2. The reactions were performed in a water medium $(60 \mathrm{~mL})$ at $160^{\circ} \mathrm{C}$ for $1 \mathrm{~h}$. When $2 \mathrm{~g}$ of the Bagasse (I) was used the imidazolium-based BAILs such as $\left[\mathrm{C}_{3} \mathrm{SO}_{3} \mathrm{HMIM}\right]\left[\mathrm{HSO}_{4}\right],\left[\mathrm{C}_{3} \mathrm{SO}_{3} \mathrm{HMIM}\right][\mathrm{PTS}]$ and $\left[\mathrm{C}_{3} \mathrm{SO}_{3} \mathrm{HMIM}\right][\mathrm{Cl}]$ exhibited higher yields of $88 \%, 81 \%$ and $75 \%$ C5 sugar (xylose + arabinose), respectively, than those catalyzed by mineral acid like $\mathrm{H}_{2} \mathrm{SO}_{4}\left(58 \% \mathrm{C} 5\right.$ sugar yield) and solid acidic catalyst like $\mathrm{HUSY}(\mathrm{Si} / \mathrm{Al}=15)(20 \% \mathrm{C} 5 \text { sugar yield })^{19}$. In previous study $\mathrm{HCl}$ catalyst was used for the conversion of isolated hemicellulose into $\mathrm{C} 5$ sugars. The result showed lower $\mathrm{C} 5$ sugar yield (39\%) compared to $\left[\mathrm{C}_{3} \mathrm{SO}_{3} \mathrm{HMIM}\right]\left[\mathrm{HSO}_{4}\right]$ BAIL (87\% C5 sugar yield) catalyst. Hence, in the present work, $\mathrm{HCl}$ catalyst was not used for the conversion of raw biomass ${ }^{19}$. For comparison, the non-catalytic reaction showed only $10 \%$ yield of C5 sugars under similar reaction conditions, indicating that the BAIL catalysts indeed promote the conversion of Bagasse to $\mathrm{C} 5$ sugars. The reaction carried out using quaternary ammonium-based BAILs (e.g. $\left[\mathrm{C}_{3} \mathrm{SO}_{3} \mathrm{HNEt}_{3}\right]\left[\mathrm{HSO}_{4}\right]$ and $\left[\mathrm{C}_{3} \mathrm{SO}_{3} \mathrm{HNEt}_{3}\right][\mathrm{PTS}]$ ) showed lower $\mathrm{C} 5$ sugar yields (i.e. $40 \%$ and $42 \%$, respectively). This indicates that imidazolium-containing BAILs are more efficient catalysts. We suggest that the reason is that of the presence of imidazolium cation in the BAIL can have ion-dipole type of interaction with polysaccharides, thus an easier availability of $\mathrm{H}^{+}$for the hydrolysis of pentosan in raw biomass can be achieved. In contrast, in the case of quaternary ammonium-based BAILs, the structure of cations is not planar so the interaction between BAILs and polysaccharides was not so achievable and therefore showed lower yields of C5 sugars. Along with ion-dipole interaction, acid strength is also one of the factors which decide the 


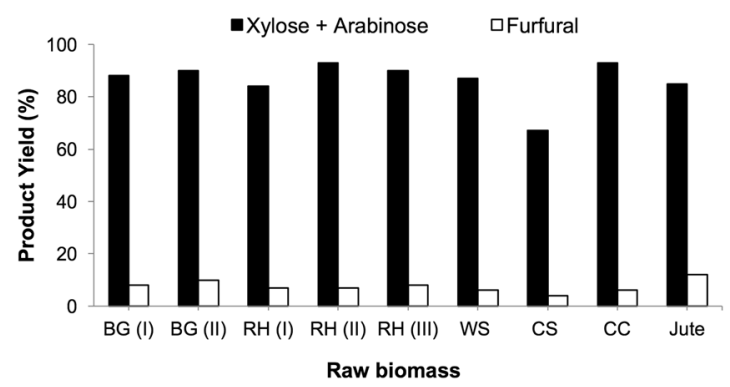

Figure 3. Processing of raw biomass into $\mathrm{C} 5$ sugars; Reaction conditions: raw biomass $(2 \mathrm{~g}), \mathrm{H}_{2} \mathrm{O}(60 \mathrm{~mL})$, $\left[\mathrm{C}_{3} \mathrm{SO}_{3} \mathrm{HMIM}\right]\left[\mathrm{HSO}_{4}\right](0.24 \mathrm{~g}), 160^{\circ} \mathrm{C}, 1 \mathrm{~h}$.

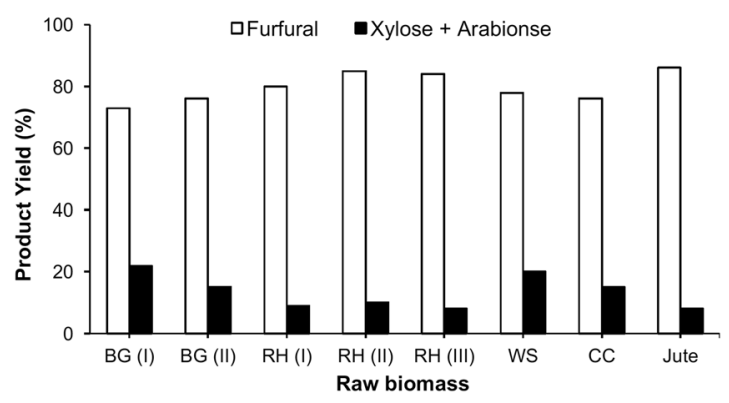

Figure 4. Processing of crop wastes into furfural; Reaction condition: crop waste (0.6 g), $\left[\mathrm{C}_{3} \mathrm{SO}_{3} \mathrm{HMIM}\left[\mathrm{HSO}_{4}\right]\right.$ $(0.12 \mathrm{~g}), \mathrm{H}_{2} \mathrm{O}$ and Toluene mixture $(1: 5 v / v ; 60 \mathrm{~mL}), 170{ }^{\circ} \mathrm{C}, 3 \mathrm{~h}$.

activity. The difference in activity among BAILs as shown in Fig. 2 can be seen because of the dissimilar acid strength of the acidic ILs. The $\left[\mathrm{C}_{3} \mathrm{SO}_{3} \mathrm{HMIM}\right]\left[\mathrm{HSO}_{4}\right]$ BAIL has highest acid strength $\left(\left[\mathrm{C}_{3} \mathrm{SO}_{3} \mathrm{HMIM}\right]\left[\mathrm{HSO}_{4}\right]\right.$ $\left.\mathrm{Ho}=2.08,\left[\mathrm{C}_{3} \mathrm{SO}_{3} \mathrm{HMIM}\right][\mathrm{PTS}] \mathrm{Ho}=2.33,\left[\mathrm{C}_{3} \mathrm{SO}_{3} \mathrm{HMIM}\right][\mathrm{Cl}] \mathrm{Ho}=2.47\right)$ and hence showed better activity compared to all other acidic ILs ${ }^{19}$. In addition, to understand the contribution of Brønsted acidity in the processing of crop waste (BG (I)) into C5 sugars, we also tested a non-Brønsted acid ionic liquid (i.e. [BMIM] [Cl]). The $[\mathrm{BMIM}][\mathrm{Cl}]$ exhibited only $21 \%$ yield, which indicated that the higher yield of $\mathrm{C} 5$ sugars was resulted from the Brønsted acidity of BAIL. Apart from C5 sugars formation, C6 sugar (glucose and fructose, 3-4\%), furfural (6-10\%) and HMF (2-3\%) were also found to be present in the final product. However, no any aromatic products derived from lignin were observed, suggesting a selective conversion of the pentosan part from bagasse to C5 sugars.

Effect of the type of raw biomass. After obtaining an exceptionally high yield of C5 sugars (88\%) from BG (I) crop waste using the $\left[\mathrm{C}_{3} \mathrm{SO}_{3} \mathrm{HMIM}\right]\left[\mathrm{HSO}_{4}\right]$ BAIL, we applied this BAIL to a wide range of crop wastes including bagasse (BG), rice husk (RH), wheat straw (WS), cotton stalk (CS), corn cob (CC) and jute. All reactions were carried out at $160^{\circ} \mathrm{C}$ for $1 \mathrm{~h}$ in a water medium $(60 \mathrm{~mL})$. As shown in Fig. 3 , the results showed that almost all types of raw biomass could be efficiently converted into C5 sugars. The yields of C5 sugars were calculated based on the amount of pentosan in raw biomass (Table S3, ESI). All the experiments were repeated 3 times, and the error in the yields of $\mathrm{C} 5$ sugars was $\pm 3 \%$. Without the addition of any mineral acid or metal halide, the method used for converting raw biomass such as bagasse, rice husk, wheat straw, cotton stalk, corn cob, and jute into C5 sugars is efficient with an average yield above $80 \%$. Furthermore, we have confirmed that only hemicellulose in crop waste was converted into C5 sugars while lignin present in crop waste remained intact. This developed method can be further scaled up for producing C5 sugars with a very high yield from pentosan-rich raw biomass.

Processing of raw biomass into furfural. After selectively converting raw biomass into C5 sugars using $\left[\mathrm{C}_{3} \mathrm{SO}_{3} \mathrm{HMIM}\right]\left[\mathrm{HSO}_{4}\right]$ BAIL successfully, we further exploited $\left[\mathrm{C}_{3} \mathrm{SO}_{3} \mathrm{HMIM}\right]\left[\mathrm{HSO}_{4}\right]$ BAIL for the conversion of hemicellulose in raw biomass into furfural. A variety of raw biomass $(0.6 \mathrm{~g})$ including bagasse (BG), rice husk (RH), wheat straw (WS), cotton stalk (CS), corn cob (CC) and jute were used as reactants, and the conversion was performed at $170{ }^{\circ} \mathrm{C}$ for $3 \mathrm{~h}$ in a water/toluene biphasic system with the presence of the $\left[\mathrm{C}_{3} \mathrm{SO}_{3} \mathrm{HMIM}\right]\left[\mathrm{HSO}_{4}\right]$ BAIL $(0.12 \mathrm{~g})$. As shown in Fig. 4 , the results clearly indicated that almost all types of raw biomass were successfully converted into furfural with very high yields (73-88\%). Rice husk collected from agricultural field of different places of India [RH (I, II, and III)] showed $>80 \%$ furfural yield while the bagasse collected from agricultural field of different places of India [BG (I, II)] showed $73 \%$ and $76 \%$ furfural yield along with $22 \%$ and $15 \%$ C5 sugar yield, respectively. Jute obtained from Bangladesh showed $86 \%$ furfural yield. Finally, the wheat straw and corn cob derived biomass showed $78 \%$ and $76 \%$ furfural yield along with $20 \%$ and $15 \%$ C5 sugar yield, respectively. 


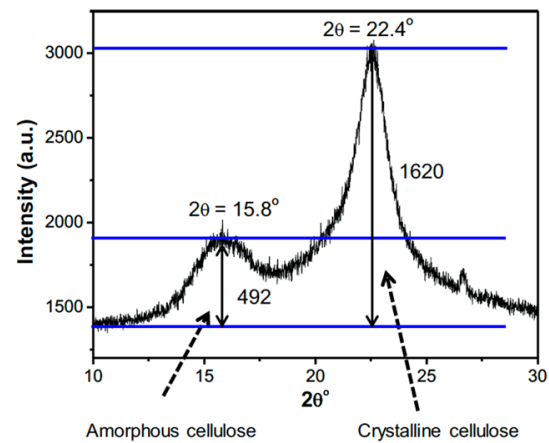

a) XRD of Fresh BG (I)

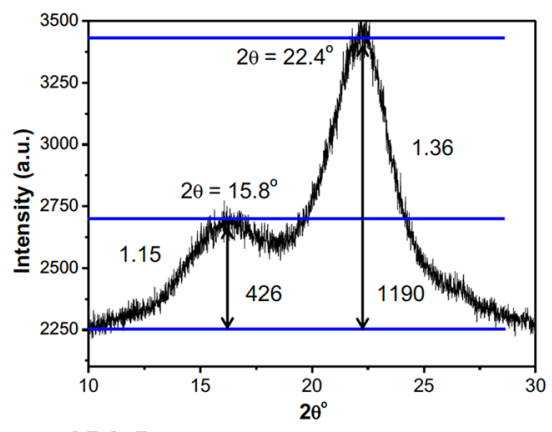

b) XRD of Recovered BG (I)

Figure 5. XRD patterns of (a) fresh and $(\mathbf{b})$ recovered BG (I). Reaction condition: $B G(\mathrm{I})(2 \mathrm{~g}),\left[\mathrm{C}_{3} \mathrm{SO}_{3} \mathrm{HMIM}\right]$ $\left[\mathrm{HSO}_{4}\right](0.24 \mathrm{~g}), \mathrm{H}_{2} \mathrm{O}(60 \mathrm{~mL}), 170^{\circ} \mathrm{C}, 3 \mathrm{~h}$.

Our $\left[\mathrm{C}_{3} \mathrm{SO}_{3} \mathrm{HMIM}\right]\left[\mathrm{HSO}_{4}\right]$ BAIL catalyst exhibited its superior ability to convert various raw biomass to furfural in one-step reaction.

In the reaction of the selective conversion of hemicellulose in BG (I) into furfural reaction, over $99 \%$ conversion of pentosan was achieved, and $73 \%$ yield of furfural along with $22 \%$ yield of C5 sugars was obtained. In contrast, cellulose and lignin in BG (I) were intact because no products derived from cellulose and lignin were found in a substantial amount. In these reactions, the mass of solid recovered after the reaction was calculated the result suggests that $98 \%$ mass balance was achieved. For example, $0.6 \mathrm{~g} \mathrm{BG}$ (I) (which contains $0.145 \mathrm{~g}$ pentosane and $0.455 \mathrm{~g}$ cellulose and lignin, respectively) was used for the reaction. After reaction, $0.451 \mathrm{~g}$ of solid was recovered. This result showed that only pentosan was consumed and all the other parts such as cellulose and lignin remained intact.

Pretreatment of cellulose. The pentosan presenting in raw biomass was completely converted into C5 sugars and furfural using $\left[\mathrm{C}_{3} \mathrm{SO}_{3} \mathrm{HMIM}\right]\left[\mathrm{HSO}_{4}\right]$ BAILs. Along with $\mathrm{C} 5$ sugars and furfural, $4-6 \%$ yield of $\mathrm{C} 6$ sugars (glucose and fructose) was also detected when the reaction temperature and time increased to $170{ }^{\circ} \mathrm{C}$ and $3 \mathrm{~h}$, respectively. This result suggests that cellulose can be converted into sugars when the temperature and time of the reaction are increased. To understand how much the cellulose exactly converted into products from raw biomass, the reaction of pure microcrystalline cellulose was performed under similar reaction conditions $\left(170{ }^{\circ} \mathrm{C}, 3 \mathrm{~h}\right)$ using the $\left[\mathrm{C}_{3} \mathrm{SO}_{3} \mathrm{HMIM}\right]\left[\mathrm{HSO}_{4}\right]$ BAIL catalyst. The result showed $10 \%$ conversion of cellulose and $7 \%$ yield of the products including glucose, fructose and HMF. This implies that very little cellulose was converted in the presence of BAIL catalyst.

To understand the structural change of cellulose in BG (I) upon catalytic reaction, the crystallinity of cellulose in BG (I) was examined before and after the reaction. The process used for the recovery of solid from reaction for XRD analysis is explained as follows: $2.0 \mathrm{~g}$ of $\mathrm{BG}(\mathrm{I})$ was used for the reaction, and after the reaction solid was separated using filtration. The solid recovered from the reaction mixture was then dried at $60^{\circ} \mathrm{C}$ for $16 \mathrm{~h}$. Next, the solid was vacuum dried at $100^{\circ} \mathrm{C}$ for $12 \mathrm{~h}$ before XRD analysis. As shown in Fig. 5(a), there are peaks for fresh BG (I) sample in the XRD, showing the amorphous and crystalline cellulose peaks at $15.8^{\circ}$ and $22.4^{\circ}$, respectively. After the catalytic conversion of $\mathrm{BG}(\mathrm{I})$ with the $\left[\mathrm{C}_{3} \mathrm{SO}_{3} \mathrm{HMIM}\right]\left[\mathrm{HSO}_{4}\right] \mathrm{BAIL}$ at $170^{\circ} \mathrm{C}$ for $3 \mathrm{~h}$, the residual sample exhibited same XRD peaks for amorphous and crystalline cellulose (i.e. same peak position but lower peak intensity), as shown in Fig. 5(b). The decrease of the XRD peak intensity indicated that the crystallinity of cellulose decreased after the catalytic reaction in the presence of the $\left[\mathrm{C}_{3} \mathrm{SO}_{3} \mathrm{HMIM}\right]\left[\mathrm{HSO}_{4}\right]$ BAIL catalyst.

Many studies have reported that the imidazolium-based ILs are useful for the pretreatment of crystalline cellulose, which decreases the crystallinity of cellulose ${ }^{22-24}$. This is because that ILs can facilitate the solubility of cellulose and increase the hydrolysis of cellulose in the presence of an acid catalyst. However, generally a huge quantity of ILs is required for such pretreatment (e.g. $2 \mathrm{~g}$ IL for $0.1 \mathrm{~g}$ cellulose). In this study, it is showed that a small amount of BAIL such as $\left[\mathrm{C}_{3} \mathrm{SO}_{3} \mathrm{HMIM}\right]\left[\mathrm{HSO}_{4}\right]$ can also decrease the crystallinity of cellulose in raw biomass, although there was very little cellulose conversion. 


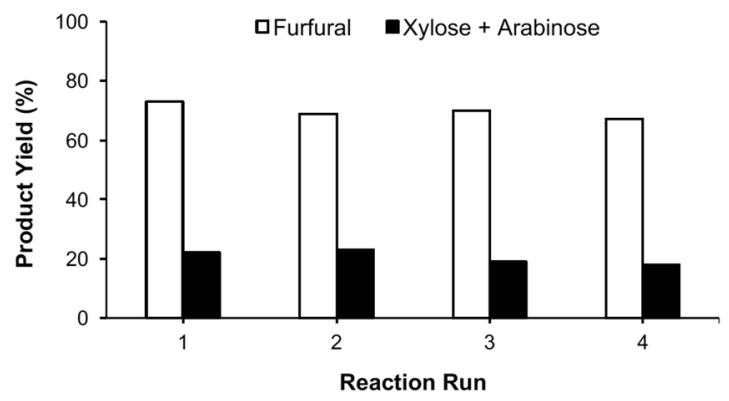

Figure 6. Recycle study for $\left[\mathrm{C}_{3} \mathrm{SO}_{3} \mathrm{HMIM}\right]\left[\mathrm{HSO}_{4}\right]$ BAIL used for processing of $\mathrm{BG}$ (I) into furfural; Reaction condition: $\mathrm{BG}(\mathrm{I}) /\left[\mathrm{C}_{3} \mathrm{SO}_{3} \mathrm{HMIM}\right]\left[\mathrm{HSO}_{4}\right](4.8 \mathrm{wt} \%), \mathrm{H}_{2} \mathrm{O}$ and Toluene mixture $(1: 5 \mathrm{v} / \mathrm{v}) 170{ }^{\circ} \mathrm{C}, 3 \mathrm{~h}$.

\begin{tabular}{|l|l|l|l|}
\hline $\begin{array}{l}\text { Nutrients } \\
(\mathbf{m m o l} / \mathrm{g})\end{array}$ & $\begin{array}{l}\text { Fresh BG } \\
(\mathrm{I})\end{array}$ & $\begin{array}{l}\text { Reaction } \\
\text { mixture }\end{array}$ & $\begin{array}{l}\text { Recovered solid from } \\
\text { reaction mixture }\end{array}$ \\
\hline $\mathrm{Na}$ & 0 & 0 & 0 \\
\hline $\mathrm{K}$ & 0.03 & 0.01 & 0.02 \\
\hline $\mathrm{Ca}$ & 0.03 & 0.01 & 0.02 \\
\hline $\mathrm{Mg}$ & 0.02 & 0 & 0.02 \\
\hline $\mathrm{Al}$ & 0.01 & 0 & 0.01 \\
\hline $\mathrm{P}$ & 0.01 & 0 & 0.01 \\
\hline
\end{tabular}

Table 1. ICP-OES results for metal exchange study. ICP-OES analysis; calculations were done based on $1 \mathrm{~g}$ of BG (I).

Recycle study for $\left[\mathrm{C}_{3} \mathrm{SO}_{3} \mathrm{HMIM}\right]\left[\mathrm{HSO}_{4}\right]$ BAIL. Recycling the catalyst is always an important issue for a novel catalyst, so we performed the recycling experiments of the $\left[\mathrm{C}_{3} \mathrm{SO}_{3} \mathrm{HMIM}\right]\left[\mathrm{HSO}_{4}\right]$ BAIL catalyst in this study. After the first reaction, the solid present in the reaction mixture was separated using filtration, and then the toluene and water layers were separated using a separating funnel. Because the furfural is soluble in toluene and the $\left[\mathrm{C}_{3} \mathrm{SO}_{3} \mathrm{HMIM}\right]\left[\mathrm{HSO}_{4}\right]$ BAIL is not soluble in toluene, a small amount of furfural soluble in aqueous layer was extracted using fresh toluene solvent (3 times extraction). The residual aqueous layer contained soluble IL and a few sugars. This water-containing IL was then used for the next reaction (Fig. S6, ESI). Subsequent reactions were carried out by decreasing the substrate and solvent quantity (to keep substrate/catalyst ratio and the substrate/ solvent ratio constant). As the quantity of aqueous layer decreased in every subsequent reaction, accordingly the substrate and solvent quantity were changed. The C5 sugars presenting in aqueous layer was considered for calculating the final yield of furfural.

The reactions were carried out at $170^{\circ} \mathrm{C}$ for $3 \mathrm{~h}$ in the water/toluene biphasic solvent system, and the substrate to catalyst ratio was kept constant for all reactions. As shown in Fig. 6, the recycle test showed an almost similar yield of furfural for the first 4 runs. The yield of furfural was $73 \%$ in the very beginning. In the first recycle run $69 \%$ furfural yield was obtained, and in the second and third recycle runs $70 \%$ and $67 \%$ furfural yields were obtained, respectively. In addition, 18-22\% C5 sugar yields were obtained for all reactions. The results of recycle test indeed indicated that the recyclability and stability of the presenting $\left[\mathrm{C}_{3} \mathrm{SO}_{3} \mathrm{HMIM}\right]\left[\mathrm{HSO}_{4}\right]$ BAIL.

Study of metal exchange. As the BAILs used in the present study are acidic in nature because of the presence of the $-\mathrm{SO}_{3} \mathrm{H}$ group, there may be a possibility that $\mathrm{H}^{+}$of BAILs can be exchanged with the metal ions which are presenting in the raw biomass. The loss of $\mathrm{H}^{+}$can therefore destroy the acid sites of BAIL. For this reason, we attempt to understand whether there is an exchange of $\mathrm{H}^{+}$of BAILs with metal ions in the reaction mixture (i.e. processed $\mathrm{BG}(\mathrm{I})$ into furfural using $\left[\mathrm{C}_{3} \mathrm{SO}_{3} \mathrm{HMIM}\right]\left[\mathrm{HSO}_{4}\right]$ BAIL) using ICP-OES technique. As presented in Table 1, very little quantity of metal nutrients is presenting in BG (I) (i.e. $0.06 \mathrm{mmol}$ for $0.6 \mathrm{~g}$ of BG (I)). ICP-OES results showed that $\mathrm{K}(0.01 \mathrm{mmol} / \mathrm{g})$ and $\mathrm{Ca}(0.01 \mathrm{mmol} / \mathrm{g})$ were found in reaction solution but their quantity is again very less $[0.012 \mathrm{mmol} \mathrm{K}$ and $\mathrm{Ca}$ for $0.6 \mathrm{~g} \mathrm{BG}(\mathrm{I})]$ Other than these two metal ions, there was no other metal ion detected in the reaction solution. This result indicated that there was a very low possibility for a considerable exchange of metals with the $\mathrm{H}^{+}$of BAILs. Thus, BAILs can be recycled and retained good catalytic ability for the selective conversion of raw biomass to furfural.

\section{Conclusion}

In this study, a successful and efficient method for the conversion of various kinds of raw biomass to $\mathrm{C} 5$ sugars and then to furfural in one-pot reaction using a series of BAILs was demonstrated. The $\left[\mathrm{C}_{3} \mathrm{SO}_{3} \mathrm{HMIM}\right]\left[\mathrm{HSO}_{4}\right]$ BAIL showed the best results compared to all other ILs because of its acidic nature and planar structure of imidazolium cation. In the processing of $\mathrm{BG}(\mathrm{I})$ into $\mathrm{C} 5$ sugars using the $\left[\mathrm{C}_{3} \mathrm{SO}_{3} \mathrm{HMIM}\right]\left[\mathrm{HSO}_{4}\right]$ BAIL catalyst, the maximum yield of $\mathrm{C} 5$ sugar was $88 \%$ under the conditions of $160^{\circ} \mathrm{C}$ within $1 \mathrm{~h}$. This value is higher than those catalyzed by conventional solid heterogeneous catalyst $\mathrm{HUSY}(\mathrm{Si} / \mathrm{Al}=15)$ and homogeneous catalyst $\mathrm{H}_{2} \mathrm{SO}_{4}$ (i.e. 
$20 \%$ and $58 \%$, respectively). Moreover, it is also demonstrated that the $\left[\mathrm{C}_{3} \mathrm{SO}_{3} \mathrm{HMIM}\right]\left[\mathrm{HSO}_{4}\right]$ BAIL catalyst can be applied to various kinds of raw biomass including bagasse, rice husk, wheat straw, cotton stalk, corn cob, and jute with an exceptionally high yield of C5 sugars (67-93\%) and furfural (76-86\%). In present system, no mineral acid or metal halides were used. And the $\left[\mathrm{C}_{3} \mathrm{SO}_{3} \mathrm{HMIM}\right]\left[\mathrm{HSO}_{4}\right]$ BAIL catalyst can be successfully recycled, indicating current method is more environmentally friendly and efficient that would be useful for other acid-assisted catalytic reactions.

\section{Experimental}

Materials and Method. For the raw biomass conversion, various types of raw biomass including rice husk, wheat straw, bagasse, cotton stalk, corn cob, and jute that were previously collected from agricultural fields located in different parts of India and Bangladesh are used. Before the experiments, the raw biomass was shattered using a mixer grinder and sieved to obtain ca. $2 \mathrm{~mm}$ size particles. Next, the raw biomass was washed (for removing residual sugars) with water at room temperature and dried in an oven at $60{ }^{\circ} \mathrm{C}$ for $16 \mathrm{~h}$ prior to being vacuum dried at $80^{\circ} \mathrm{C}$ for $16 \mathrm{~h}$. Afterward, these crop wastes were used in the reaction.

The materials and detailed synthesis procedure of BAIL are described in Section 2 \& 3, ESI (Table S2 and Fig. S1). The synthesized BAILs were characterized with NMR $\left({ }^{1} \mathrm{H},{ }^{13} \mathrm{C}\right)$, FTIR, TGA, CHNS microanalysis and other analysis methods. for confirming the structure and stability of the BAILs ${ }^{20}$.

All the catalytic reactions were carried out at high pressure and high-temperature batch mode autoclave (Parr autoclave; $300 \mathrm{~mL}$ capacity) equipped with temperature manager unit. In a normal reaction, for the processing of raw biomass into $\mathrm{C} 5$ sugars, $2 \mathrm{~g}$ of biomass was charged in the reactor and then $60 \mathrm{~mL}$ of water along with $0.24 \mathrm{~g}$ catalyst (BAIL) was added to the reactor. For the processing of raw biomass into furfural in the one-pot method, $0.6 \mathrm{~g}$ of raw biomass was charged in the reactor and then the water and toluene biphasic solvent was added $(60 \mathrm{~mL}$; $1: 5 \mathrm{v} / \mathrm{v}$ ) along with $0.12 \mathrm{~g}$ catalyst (BAIL). Reactions were performed at desired reaction temperature $\left(160^{\circ} \mathrm{C}\right.$ and $\left.170^{\circ} \mathrm{C}\right)$ for definite reaction time $(1 \mathrm{~h}$ and $3 \mathrm{~h})$ under mechanical stirring $(800 \mathrm{rpm})$.

Analysis. The analysis of samples was performed using HPLC instrument (Agilent) equipped with a Rezex $\mathrm{RPM}$-Monosaccharide $\mathrm{Pb}^{2+}$ column $(300 \times 7.8 \mathrm{~mm}$; particle size $8 \mu \mathrm{m})$ at $80^{\circ} \mathrm{C}$. Millipore water was used as an eluent with a flow rate of $0.6 \mathrm{~mL} / \mathrm{min}$. The refractive index detector (RID) with a cell temperature of $40^{\circ} \mathrm{C}$ was used to detect the products. Before analysis, the samples were filtered through $0.22 \mu \mathrm{m}$ syringe filter, which was then injected for the analysis. The calibration curve was plotted with the standard compounds for calculating the yield of products. The Gas chromatography (GC) equipped with HP-5 column was used for the analysis of the organic layer of the reaction mixture. The Flame Ionization Detector with the temperature $280^{\circ} \mathrm{C}$ was used for the examination of verity of products.

Calculations. The yield of sugars obtained by selective conversion of hemicellulose from crop waste was calculated based on the concentration of pentosan presenting in the raw biomass. Technical Association of the Pulp and Paper Industry (TAPPI) method was used for deciding the pentosan concentration in all raw biomass. The calculations of C5 sugar yield and furfural yield are shown in the Section 4 of ESI.

Compositional analysis of raw biomass. TAPPI method was used to understand the composition of raw biomass (holocellulose, pentosan, lignin, ash, etc.) (more details are given in ESI Section 5). Various metal nutrients are used for the growth of plants, so there is a possibility of the presence of various metal nutrients in the non-edible biomass. The metal nutrients presenting in raw biomass were determined by ICP-OES analysis (Table S4, ESI)

\section{References}

1. Li, X., Jia, P. \& Wang, T. Furfural: A Promising Platform Compound for Sustainable Production of C4 and C5 Chemicals. ACS Catal. 6, 7621-7640 (2016).

2. Lima, S. et al. Dehydration of Xylose into Furfural in the Presence of Crystalline Microporous Silicoaluminophosphates. Catal. Lett. 135, 41-47 (2010).

3. Dias, A. S., Pillinger, M. \& Valente, A. A. Dehydration of xylose into furfural over micro-mesoporous sulfonic acid catalysts. J. Catal. 229, 414-423 (2005).

4. Peleteiro, S., Rivas, S., Alonso, J. L., Santos, V. \& Parajó, J. C. Furfural production using ionic liquids: A review. Bioresour. Technol. 202, 181-191 (2016).

5. Wettstein, S. G., Alonso, D. M., Gürbüz, E. I. \& Dumesic, J. A. A roadmap for conversion of lignocellulosic biomass to chemicals and fuels. Curr. Opin. Chem. Eng. 1, 218-224 (2012).

6. Gallo, J. M. R. et al. Production of Furfural from Lignocellulosic Biomass Using Beta Zeolite and Biomass-Derived Solvent. Top. Catal. 56, 1775-1781 (2013).

7. Fanta, G. F., Abbott, T. P., Herman, A. I., Burr, R. C. \& Doane, W. M. Hydrolysis of wheat straw hemicellulose with trifluoroacetic acid. Fermentation of xylose with Pachysolen tannophilus. Biotechnol. Bioeng. 26, 1122-1125 (1984).

8. Nguyen, C. V. et al. Combined treatments for producing 5-hydroxymethylfurfural (HMF) from lignocellulosic biomass. Catal. Today 278, Part 2, 344-349 (2016).

9. Dutta, S., Bhaumik, A. \& Wu, K. C. W. Hierarchically porous carbon derived from polymers and biomass: effect of interconnected pores on energy applications. Energy Environ. Sci. 7, 3574-3592 (2014).

10. Chang, R. H.-Y., Jang, J. \& Wu, K. C. W. Cellulase immobilized mesoporous silica nanocatalysts for efficient cellulose-to-glucose conversion. Green Chemistry 13, 2844-2850 (2011).

11. da Costa Sousa, L., Chundawat, S. P., Balan, V. \& Dale, B. E. 'Cradle-to-graveassessment of existing lignocellulose pretreatment technologies. Curr. Opin. Biotechnol. 20, 339-347 (2009).

12. Sahu, R. \& Dhepe, P. L. A One-Pot Method for the Selective Conversion of Hemicellulose from Crop Waste into C5 Sugars and Furfural by Using Solid Acid Catalysts. ChemSusChem 5, 751-761 (2012).

13. Bhaumik, P. \& Dhepe, P. L. In Biomass Sugars for Non-Fuel Applications 1-53 RSC (2016).

14. Zhang, L., Yu, H., Wang, P., Dong, H. \& Peng, X. Conversion of xylan, d-xylose and lignocellulosic biomass into furfural using $\mathrm{AlCl}_{3}$ as catalyst in ionic liquid. Bioresour. Technol. 130, 110-116 (2013). 
15. Zhang, L., Yu, H. \& Wang, P. Solid acids as catalysts for the conversion of d-xylose, xylan and lignocellulosics into furfural in ionic liquid. Bioresour. Technol. 136, 515-521 (2013).

16. Jiang, Y. et al. Direct conversion of chitosan to 5-hydroxymethylfurfural in water using Bronsted-Lewis acidic ionic liquids as catalysts. RSC Adv. 6, 103774-103781 (2016)

17. Matsagar, B. M., Munshi, M. K., Kelkar, A. A. \& Dhepe, P. L. Conversion of concentrated sugar solutions into 5-hydroxymethyl furfural and furfural using Bronsted acidic ionic liquids. Catal. Sci. Technol. 5, 5086-5090 (2015).

18. Serrano-Ruiz, J. C. et al. Efficient microwave-assisted production of furfural from C5 sugars in aqueous media catalysed by Bronsted acidic ionic liquids. Catal. Sci. Technol. 2, 1828-1832 (2012).

19. Matsagar, B. M. \& Dhepe, P. L. Brönsted acidic ionic liquid-catalyzed conversion of hemicellulose into sugars. Catal. Sci. Technol. 5, 531-539 (2015).

20. Matsagar, B. M. \& Dhepe, P. L. Effects of cations, anions and $\mathrm{H}^{+}$concentration of acidic ionic liquids on the valorization of polysaccharides into furfural. New J. Chem. 41, 6137-6144 (2017).

21. Food and Agriculture Organization of the United Nations, http://faostat3.fao.org/download/Q/QC/E (2014).

22. Liu, Y., Xiao, W., Xia, S. \& Ma, P. SO3H-functionalized acidic ionic liquids as catalysts for the hydrolysis of cellulose. Carbohydr. Polym. 92, 218-222 (2013).

23. Li, C., Zhang, Z. \& Zhao, Z. K. Direct conversion of glucose and cellulose to 5-hydroxymethylfurfural in ionic liquid under microwave irradiation. Tetrahedron Lett. 50, 5403-5405 (2009).

24. Hsu, W.-H., Lee, Y.-Y., Peng, W.-H. \& Wu, K. C. W. Cellulosic conversion in ionic liquids (ILs): Effects of $\mathrm{H}_{2} \mathrm{O} /$ cellulose molar ratios, temperatures, times, and different ILs on the production of monosaccharides and 5-hydroxymethylfurfural (HMF). Catal. Today 174, 65-69 (2011).

\section{Acknowledgements}

We would like to thank the Ministry of Science and Technology (MOST) of Taiwan (104-2628-E-002-008-MY3; 105-2218-E-155-007; 105-2221-E-002-003-MY3; 105-2221-E-002-227-MY3; 105-2622-E-155-003-CC2) and the Aim for Top University Project at National Taiwan University (105R7706) for the funding support. We are thankful to the World Bank for partial funding of this work through a subproject of Higher Education Quality Enhancement Project (HEQEP), Complete Proposal \#2071. Z.A.A. is grateful to the Deanship of Scientific Research, King Saud University for funding through Vice Deanship of Scientific Research Chairs.

\section{Author Contributions}

B.M. and M.H. conceived and designed the experiments. The manuscript was written through contributions of all authors. M.I., Y.Y. edited the figures. P.D. and K.W. revised the manuscript. All authors have given approval to the final version of the manuscript.

\section{Additional Information}

Supplementary information accompanies this paper at https://doi.org/10.1038/s41598-017-13946-4.

Competing Interests: The authors declare that they have no competing interests.

Publisher's note: Springer Nature remains neutral with regard to jurisdictional claims in published maps and institutional affiliations.

(c) (i) Open Access This article is licensed under a Creative Commons Attribution 4.0 International License, which permits use, sharing, adaptation, distribution and reproduction in any medium or format, as long as you give appropriate credit to the original author(s) and the source, provide a link to the Creative Commons license, and indicate if changes were made. The images or other third party material in this article are included in the article's Creative Commons license, unless indicated otherwise in a credit line to the material. If material is not included in the article's Creative Commons license and your intended use is not permitted by statutory regulation or exceeds the permitted use, you will need to obtain permission directly from the copyright holder. To view a copy of this license, visit http://creativecommons.org/licenses/by/4.0/.

(C) The Author(s) 2017 